\title{
Some Notes on Modelling the Relationship between the Environment and Institutional Context
}

\author{
Davide Infante, Janna Smirnova \\ Department of Economics and Statistics, University of Calabria, Arcavacata di Rende (Cosenza), Italy \\ E-mail:d.infante@unical.it,smirnova@unical.it \\ Received January 13, 2011; revised January 23, 2011; accepted January 26, 2011
}

\begin{abstract}
Being a real concern of any society, environmental quality has received much attention in economic literature. However, the role that the institutional context plays in environmental issues is still an open question. Since the environment and institutional context are closely interrelated through government regulation, the investigation on the relationship between environment-institutions represents a fruitful terrain for economic research. Our aim is to design research notes to study this relationship using theoretical and empirical approaches, by modelling the institutional context and estimating its impact on the environment. Our notes could also shed fresh light on the issue of environmental policies and their implementation in emerging and developing economies.
\end{abstract}

Keywords: Institutional Context, Environmental Polices, Pollution, Sustainable Development

\section{Introduction}

Issues regarding the quality of the environment represent a real and current concern for modern society. The existence of trade-offs between economic growth and environment, can lead conflict situations and market failures. The achievement of an equilibrium of these trade-offs is possible however through government regulation. The implementation of economic policies by the regulator, in turn, depends on the quality of the institutional context that exists in a given society. Therefore, the analysis of the relationship between environmental and institutional aspects is important to achieve the goal of sustainable economic development.

In these notes we analyse the relationship between the environment and institutional context at theoretical and empirical level. In particular, we aim to demonstrate how the reinforcement of the institutional context influences the application of environmental policies and the diffusion of new technologies, and to verify the impact of institutions on the quality of the environment and, therefore, on social welfare.

The impact of the institutional context on the environment is one of the open questions in economic literature that tends to focus on specific cases and sectors and analyses single institutions or sets. Instead, a more complex analysis of institutions and their interaction with environment may be necessary to understand the internal processes involved and to propose variants of environmental policies to increase social welfare. Two interdependent reasons support this argument. First, the application of instruments for environmental protection rarely occurs without state intervention and, therefore, must comply with regulation. Second, regulation, in turn, greatly depends on the strength of the institutional context in society. These arguments make it necessary to provide a more complete analysis of the effects of institutional context on environmental policies as well as on evaluating its impact on environmental quality.

To reach these goals, we move in three research directions. The first considers the construction of a theoretical model to show that environmentally friendly technology adoption by firms is heavily dependent upon the degree to which the rules are enforced.

The second direction of the research offers a mathematical simulation of the theoretical model and illustrates how the reinforcement of the institutional context influences the adoption of environmental technologies, the application of environmental taxes and subsidies and the standard of pollution abatement.

The third direction is dedicated to the empirical analysis of the relationship between the environment-institutional context and offers an econometric estimation of two models. The first is built to study the cointegration 
between the institutional context, instruments for environmental protection and economic performance. The second econometric model analyses the impact of the institutional context on pollution levels to estimate how the quality of the institutional context influences emission levels and identifies its impact on the position of the turning point of the Environmental Kuznets Curve (EKC).

\section{Critical Literature Review}

A definition of the characteristics of the institutional context that influence positively environmental protection is of great interest both in developing and developed countries. In fact, the creation of strong institutions, through clear legislation, financial and political stability, defined property rights and a stable banking system, is considered to be one of the most effective instruments of environmental protection. Recent studies demonstrate that the development of the institutions is a complex process that does not follow any single rule and differs from country to country, which creates difficulties in defining and analysing the institutional context.

\subsection{Theoretical and Empirical Research on Institutions}

While empirical research on the effects of the institutional context on economic performance is well developed, theoretical research in this field is quite limited. The theoretical approach usually concentrates on the analysis of a single institution or a set of institutions and does not consider the entire institutional context. Difficulties in measuring and ambiguity in defining institutions are probably responsible for this.

Public institutions are frequently analysed in models that describe the influence of institutions on economic performance [1,2]. A part of this research concentrates on the effects of corruption [3] and rent-seeking [4]. These studies confirm the negative impact of legal and illegal rent-seeking on economic performance, even though some authors [5,6] find a positive influence, mostly in the short term, confirming that the reinforcement of the institutional context is necessary in the long run [7].

Another type of institution analysed in the literature is the rule of law which is fundamental for the implementation of environmental policies. The rule of law is usually measured in terms of the protection of property rights. Among the most important studies in this field are those of [8] and [9], which confirm the importance of property rights protection for economic growth. Other studies consider the rule of law to be the application of contracts that limit conflicts in society [10], or the legitimacy with which the regulator provides security for citizens [11]. Finally, the rule of law is considered by [12] and [13] to be the foundation of a society's legal origins. Although there are many studies dedicated to the rule of law, to the best of our knowledge, there is no work that analyses this institution specifically in terms of the environment.

Undoubtedly, the above models make an important contribution towards exploring the links between institutions and economic performance, but they represent only a partial analysis of the institutional context. An exception is the [14] model of organisational choice that describes the entire institutional context by utilising a parameter that reflects institutions in general, given that it refers to corruption, the legal system, economic stability and other factors simultaneously. Following [15], who introduce the parameter as measure of institutional strength, we take the [14] approach as a point of departure for institutional modelling.

As for empirical research, various models have been developed to analyse the impact of institutions on economic performance. It is important to stress that the complex nature and behaviour of institutions leads to wide divergences from one author to the next. The variables that reflect the institutional context are often based on indices, evaluation by experts and ratings. Therefore, empirical analysis often results in a correlation between independent variables, rendering the models less robust. Among the studies in this field, the institutions that are usually analysed are property rights [9], legal origins [16], cultural aspects [17] and economic stability [18]. A large number of models study the impact of the rule of law, property rights protection and corruption [19-22] on economic growth. Yet, there is no model that aims to test the effects of a wide range of institutions in order to obtain a picture of the broader institutional context.

\subsection{Research on Environment and Institutional Context}

The analysis of the links between the environment and the institutional context is still largely unexplored, particularly at the theoretical level. This is due to the difficulties in introducing an institutional context into theoretical models, given that current literature does not clearly define what the institutional context is or how it is measured. Empirical models that aim to demonstrate results achieved at a theoretical level encounter other difficulties. While generally there is no problem collecting data on institutions, there is a problem with the availability of data about environmental policies and instruments of environmental protection at international level. In fact, most empirical studies concentrate on data in specific sectors. As a consequence, the models that 
study links between the environment and institutions have problems covering both theoretical and empirical approaches and do not fully capture the relationship between the institutional context and the environment.

Among the studies of interest is that of [23], which presents a study on the interdependence of economic openness, income and pollution, estimating cross-country data, to verify the cointegration of these three variables and their endogeneity. The first model of the empirical part of the present research applies a similar approach but unlike from [23], focus on the links between the institutional context, economic performance and the application of instruments for environmental protection, by applying co-integration analysis for panel data.

Also crucial to the present research is the [24] model dedicated to the analysis of government policy in the adoption of environmental technology. This model evaluates the influence of economic openness on the adoption of environmental technologies in the coal industry. A similar model is that of [25], who demonstrate that the instruments for environmental protection can be more efficient in presence of more flexible state policies, taking the oil industry as an example. Other studies analyse the diffusion of new environmental technologies and the level of pollution in relation to persisting rent-seeking activities and the corruption of economic agents [25,5]. Another branch of studies analyses the participation in international environments treaties $[27,28]$. These studies are also dedicated to the environment - institutions relationship but consider only single institutions and specific environmental issues. The second empirical model of the present research aims to involve more institutions to evaluate their impact on the quality of environment and on the level of pollution at a global level.

In sum, currently there are no studies that fully capture both the theoretical and the empirical levels of the relationship between the environment and the institutional context. The present research aims to address this lacuna, and builds a theoretical model that captures the institutional context, analysing it with respect to the environmental aspects and estimating their relationship at international level.

\section{Theoretical and Empirical Modeling}

The construction of a theoretical model aims to formalise the interaction between the state and the production sector in the process of adoption of new environmental technologies at a microeconomic level, taking into consideration the institutional context. The model is represented in the form of a static game with imperfect information, created using the backward induction technique and offering a 'second-best' solution due to the presence of market failures. In particular, the model describes an economy in which firms use polluting technology, transferring a disutility to all economic agents. The regulator, whose role is to improve social welfare, provides incentives to firms to apply environmental technologies by offering subsidies to those firms that change the type of technology they use and imposing taxes on those who continue to utilise the old technology. To verify the choice of technology, the regulator employs inspectors who monitor the firms. The inspectors transfer the funds from state to production sector and vice versa.

It is assumed that the information is incomplete on three levels. The first is an uncertainty regarding the honesty of the inspector. The second is the uncertainty connected to the monitoring of the firms, a casual process. The last level concerns the quality of the institutional context, captured by the interaction between the firm and the dishonest inspector. The parameters of the institutional context are defined as a relationship between the administrative capacity of the regulator and the degree of weakness of the institutions (for example, the presence of corruption, undefined property rights, a weak legal system, and rule of law). The value of the coefficients is uncertain.

The role of the regulator is to achieve the adoption of environmentally-friendly technologies, respecting the constraints of budget, rent-seeking and technology. The regulator intervenes in the production sector only if intervention leads to an increase in social welfare. If the regulator does not intervene, the market for environmental technology fails.

In the case of state intervention, the second-best solution is influenced by the quality of the institutional context that determines the allocation of economic agents, the level of social welfare and the standard of pollution abatement. The model shows that the reinforcement of the institutional context limits the use of polluting technologies at a lower cost to the regulator and with fewer inspectors. In the case of a strong institutional context, even low pollution levels can be neutralised by intervention of the regulator.

The mathematical simulation of the model is produced to investigate how the results can change if institutional parameters are modified. Thus we simulate a scenario in which the regulator can respond to the reinforcement of the institutional context by using taxes, subsidies and efficiency wages. In this way, the simulation allows the possible environmental policies to be evaluated under different institutional conditions.

The empirical model is focused on exploring the links between the environment and the institutional context, verifying the results obtained through the theoretical approach. The model aims to measure the correlation be- 
tween the institutional context, the application of instruments of environmental protection and economic performance in low and high income countries. The comparative analysis of the results from different groups of countries is important, given that the groups differ in their institutional contexts.

It is often maintained that an increase in income in a country that is given to the reinforcement of the institutional context implies an increase in the demand for environmental protection, and therefore, for the adoption of environmentally-friendly technologies. Therefore, the reinforcement of the institutional context can create the win-win situation in the sense that it improves both the application of environmental protection instruments and the level of income of the country. Alternately, if the reinforcement of the institutional context does not coincide with an increase in income, environmental protection instruments are more difficult to apply.

In considering the instruments applied for environmental protection, we can refer to the Environmental Kuznets Curve (EKC), a concept, that emerged in the early 1990s with [29] seminal paper, positing that environmental degradation first increases and then falls with increasing per capita income. This mechanism can be similar to that of the application of instruments for environmental protection, assuming that with the increase in income the application of these instruments first goes up and, once it has reached the turning point, goes down, probably due to the reinforcement of the institutional context.

In order to illustrate the links between the institutional context, instruments for environmental protection and income, we take into consideration the institution of the rule of law and define income $(Y)$ as a function of the rule of law ( $R o L)$ and of other exogenous variables $\left(Z_{1}\right)$ :

$$
Y=f\left(R o L, Z_{1}\right)
$$

The instruments for environmental protection $(E)$ are defined as a function of income $(Y)$ and production technology $\left(Z_{2}\right)$ :

$$
E=f\left(Y, Z_{2}\right)
$$

By substituting Equation (1) in (2) the following model is obtained:

$$
E=g\left(R o L, Z_{1}, Z_{2}\right)
$$

This relationship is estimated by applying the vector autoregression model (VAR) that is considered to be suitable for the study of endogeneity and casual mechanism problems. In this model, the VAR approach can determine the dynamic effects of the variables and test their endogeneity in the long run.
Given the lack of observations regarding application of the instruments for environmental protection the analysis requires the construction of panel data. The data related to this variable were revealed only recently. The sole source of this data, to the best of our knowledge, is provided by Eurostat, which keeps statistics for five different kinds of environmental taxes from 1996 through 2008. Data related to the income of European and other world countries are provided by the World Bank. The rule of law index is provided by [30] and covers a wide range of measures, such as contract enforcement for 168 countries. The available data, however, is not complete, and requires the addition of certain variables through the application of auxiliary regressions.

The second empirical model is dedicated to the comparative analysis of the impact of the quality of institutional context on pollution levels in developing countries (including transition economies) and developed countries. This analysis is necessary because former socialist countries are defined by a persistent weak institutional context that favours rent-seeking activities that has a negative effect on the environment.

Some indicators on the institutional context are provided by the European Bank of Reconstruction and Development for the economies of Central Europe and the former Soviet Union. The indicators are based on four important factors: entrepreneurs and families, markets, financial institutions and the legal system. Based on these factors, ten international classifications of institutional context were created. As for environmental pollution, the World Bank provides data on various types of emissions among which that of carbon dioxide is the most widespread and frequently used.

The following linear model is estimated for panel data obtained for the analysis:

$$
\ln \operatorname{Pol}_{i t}=\alpha+\sum_{j=1}^{n} \beta_{j} x_{j i t}+\sum_{k=1}^{m} \gamma_{k} y_{k i t}+\varepsilon_{i t}
$$

where $\mathrm{Pol}$ is a dependent variable of environmental pollution in country $i$ at time $t, x_{j i t}$ are the sets of indicators of institutional context that influence pollution levels, and $y_{k i t}$ are country specific variables.

The existence of links between the institutional context, income and pollution are confirmed by the analyses of the first and the second empirical models. This result allows us to understand how the reinforcement of the institutional context influences the position of the EKC turning point in different groups of countries. A number of studies [31] demonstrate that some developed countries with high levels of income have already reached the turning point of pollution on the EKC and, therefore, the maximum level of application of environmental protection instruments. This may be due to the reinforcement 
of the institutional context that, as demonstrated by the theoretical model, implies lesser costs to improve the quality of environment.

\section{Preliminary Results}

The elaboration of the above models provides some important insights on the study of the relationship between institutional context and environment. Preliminary results of the theoretical model demonstrate that institutional enforcement has a significant influence on the decisions of a regulator to undertake environmental policy. Stringent institutions promote environmental policy application, leading to improvements of pollution abatement standard and of the quality of environmental protection. We also demonstrate that under a stringent rule of law, the establishment of a pollution abatement standard is more efficient and leads to the neutralization of even low levels of pollution. Moreover, with a reinforced rule of law, external harm may be neutralised with lower costs of regulator intervention not only because rentseeking activities are discouraged, but also because fewer inspectors are needed to enforce policies.

The preliminary findings of the theoretical model are confirmed by empirical estimations of the two econometric models developed, as an example, for Western and Central European countries. Preliminary results of the econometric first model confirm the presence of cointegrated relationship between environmental protection, expressed by environmental taxes [32], rule of law index [30] and income per capita [33]. Rule of law is taken into consideration given that it plays an important role in environmental policies, reflecting the quality of institutional context. The second empirical model further explores the above relationship, referring to the Environmental Kuznets Curve (see among recent studies [34-37]), investigating on income-pollution path. For the sample of European countries we find the evidence for EKC for carbon emissions [32]. Moreover, for the same data we test a similar to EKC relationship between environmental protection and income, where the amount of taxes paid for environmental protection first increases and then declines beyond a certain level of per capita income (turning point). Our results show that the behavior of the curve, and the position of the turning point, depend significantly on the stringency of institutions. In the case of strong rule of law, the turning point of the EKC occurs at a lower level of income per capita, thus, decreasing emissions.

\section{Conclusions}

These research notes have allowed us to investigate the relationship between the environment and institutional context, an issue of great importance for any contemporary society that aims to undertake sustainable economic development. Despite its importance, the economic literature does not dedicate much attention to the relationship between the environment-institutional context; this is mostly due to the problems related to the difficulties in introducing institutions in theoretical models and in obtaining environmental protection data for empirical estimations. Our work aims to overcome these lacunae and offers a way to formally build up the institutional context at theoretical level and to empirically estimate its impact on the environment.

The designed theoretical model based on microeconomic factors captures the interaction between the state and the productive sector during the process of institutional transformation. The model is expected to demonstrate that institutional reinforcement implies a more stringent adoption of environmental technologies, decreasing their costs and increasing social welfare, and leads to more efficient pollution abatement standards. Reinforced institutions decrease the cost of environmental policy implementation and limit the draining of public resources by rent-seekers.

The first empirical model is expected to demonstrate the existence of a long-term equilibrium between the rule of law and the application of instruments for environmental protection in developed and developing countries. A strengthening of the rule of law leads to a win-win situation, in which the application of instruments for environmental protection becomes more effective together with improved economic performance of the country.

The second empirical model is expected to find the extent to which different components of the institutional context influence environmental degradation in different groups of countries, investigating which institutions have crucial importance on environmental quality. This model checks for the dependence of the position of the turning point of EKC on the strength of the institutional context in different groups of countries.

By investigating the links between environment and institutional context on both theoretical and empirical levels, our research could also shed new light on the issue of environmental policies and their implementation in emerging and developing countries.

\section{References}

[1] B. Saha, "Red Tape, Incentive Bribe and the Provision of Subsidy," Journal of Development Economics, Vol. 65, No. 1, 2001, pp. 113-133. doi:10.1016/S0304-3878(01)00130-4

[2] S. Guriev, "Red Tape and Corruption,” Journal of Development Economics, Vol. 73, No. 2, 2004, pp. 489-504. 
doi:10.1016/j.jdeveco.2003.06.001

[3] B. Ventelou, "Corruption in a Model of Growth: Political Reputation, Competition and Shocks," Public Choice, Vol. 110, No. 1-2, 2002, pp. 23-40. doi:10.1023/A:1013034225646

[4] K. Hausken, "Production and Conflict Models Versus Rent-Seeking Models,” Public Choice, Vol. 123, No. 1, 2005, pp. 59-93. doi:10.1007/s11127-005-1717-3

[5] D. Acemoglu and T. Verdier, "The Choice between Market Failures and Corruption," The American Economics Review, Vol. 90, No. 1, 2000, pp. 194-211. doi:10.1257/aer.90.1.194

[6] D. Infante and J. Smirnova, "Rent-Seeking under Weak Institutional Environment,” Economics Letters, Vol. 104, No. 3, 2009, pp. 118-121. doi:10.1016/j.econlet.2009.04.022

[7] D. Infante and J. Smirnova, "Entrepreneurship, Rentseeking Spillovers and Decreasing Returns. A Microeconomic Approach," Acta Oeconomica, Vol. 59, No. 1, 2009, pp. 79-89. doi:10.1556/AOecon.59.2009.1.4

[8] M. Gradstein, “Governance and Growth”, Journal of Development Economics, Vol. 73, 2004, pp. 505-518. doi:10.1016/j.jdeveco.2003.05.002

[9] D. Acemoglu and S. Johnson, "Unbundling Institutions," NBER Working Papers Series, Working Paper 9934, 1993.

[10] M. Cervellati and P. Fortunato, "Hobbes to Rousseau: Inequality, Institutions and Development," The Economic Journal, Vol. 118, No. 531, 2008, pp. 1354-1384. doi:10.1111/j.1468-0297.2008.02173.x

[11] S. J. M. Donnelly, "Reflecting on the Rule of Law: Its Reciprocal Relation with Rights, Legitimacy, and Other Concepts and Institutions," The ANNALS of the American Academy of Political and Social Science, Vol. 603, No. 1, 2006, pp.37-53. doi:10.1177/0002716205282054

[12] D. Acemoglu, S. Johnson and J. A. Robinson, “The Colonial Origins of Comparative Development: an Empirical Investigation,” The American Economic Review, Vol. 91, No. 5, 2001, pp. 1369-1401. doi:10.1257/aer.91.5.1369

[13] S. Djankov, E. L. Glaeser, R. La Porta, F. Lopezde-Silanes and A. Shleifer, "The New Comparative Economics,” NBER Working Papers Series, Working Paper 9608, 2003.

[14] H. S. Esfahani, "Institutions and Government Controls," Journal of Development Economics, Vol. 63, No. 2, 2000, pp. 197-229. doi:10.1016/S0304-3878(00)00119-X

[15] D. Infante and J. Smirnova, "Politicians, Firms and Institutional Environment," Seoul Journal of Economics, Vol. 23, No. 3, 2010, pp. 391-406.

[16] T. Beck, A. Demirguc-Kunt and R. Levine, "Law, Endowments and Finance,” Journal of Financial Economics, Vol. 70, No. 2, 2003, pp. 137-181. doi:10.1016/S0304-405X(03)00144-2

[17] E. L. Glaeser, D. Laibson, J. A. Scheinkman and C. L. Soutter, "Measuring Trust," Quarterly Journal of Economics, Vol. 115, No. 3, 2000, pp. 811-846. doi:10.1162/003355300554926

[18] R. Damania, P. G. Fredriksson and M. Mani, “The Per- sistence of Corruption and Regulatory Compliance Failures: Theory and Evidence,” Public Choice, Vol. 121, No. 3, 2004, pp. 363-390. doi:10.1007/s11127-004-1684-0

[19] S. Knack and P. Keefer, "Institutions and Economic Performance: Cross-Country Tests Using Alternative Institutional Measures,” Economics and Politics, Vol. 7, No.3, 1995, pp. 207-227. doi:10.1111/j.1468-0343.1995.tb00111.x

[20] P. Mauro, “Corruption and Growth,” The Quarterly Journal of Economics, Vol. 110, No. 3, 1995, pp. 681- 712. doi: $10.2307 / 2946696$

[21] D. Dollar and A. Kraay, "Property Rights, Political Rights, and the Development of Poor Countries in the Post-Colonial Period," World Bank Working Papers, 2000.

[22] J. L. Butkiewicz and H. Yanikkaya, "Institutional Quality and Economic Growth: Maintenance of the Rule of Law or Democratic Institutions, or Both?” Economic Modelling, Vol. 23, No. 4, 2006, pp. 648-661. doi:10.1016/j.econmod.2006.03.004

[23] J. Baek, Y. Cho and W. W. Koo, "The Environmental Consequences of Globalisation: a Country-Specific TimeSeries Analysis” Ecological Economics, Vol. 68, No. 8-9, 2009, pp. 2255-2264. doi:10.1016/j.ecolecon.2009.02.021

[24] M. Lovely and D. Popp, “Trade, Technology and the Environment: Why Have Poor Countries Regulated Sooner?” NBER Working Papers Series, 14286, 2008.

[25] S. Kerr and R. G. Newell, "Policy-Induced Technology Adoption: Evidence from the U.S. Lead Phasedown,” Journal of Industrial Economics, Vol. 51, No. 3, 2003, pp. 317-343. doi:10.1111/1467-6451.00203

[26] D. Mookherjee and I. P. L. Png, “Corruptible Law Enforcers: How Should They be Compensated?” Economic Journal, Vol. 105, No. 428, 1995, pp. 145-159. doi: $10.2307 / 2235324$

[27] C. Carraro, C. Marchiori and S. Oreffice, "Endogenous Minimum Participation in International Environmental Treaties," Environmental and Resource Economics, Vol. 42, No. 3, 2009, pp. 411-425. doi:10.1007/s10640-009-9264-X

[28] M. Finus, "Game Theoretic Research on the Design of International Environmental Agreements: Insights, Critical Remarks and Future Challenges," International Review of Environmental and Resource Economics, Vol. 2, No. 1, 2008, pp. 1-39. doi:10.1561/101.00000011

[29] G. M. Grossman and A. B. Krueger, "Environmental impacts of a North American Free Trade Agreement," NBER Working Paper, 3914, Cambridge, MA, 1991.

[30] D. Kaufmann, A. Kraay and M. Mastruzzi, "Governance Matters III: Governance Indicators for 1996-2002,” World Bank Policy Research Department Working Paper, 2009.

[31] S. Dinda, "Environmental Kuznets Curve Hypothesis: a survey,” Ecological Economics, Vol. 49, No. 4, 2004, pp. 431-455. doi:10.1016/j.ecolecon.2004.02.011

[32] Eurostat, "Eurostat Statistics,” 2010. Available online.

[33] World Bank, “World Development Indicators,” 2010. Available online. 
[34] R. Lopez and S. Mitra, "Corruption, Pollution, and Kuznets Environment Curve,” Journal of Environmental Economics and Management, Vol. 40, No. 2, 2000, pp. 137-150. doi:10.1006/jeem.1999.1107

[35] D. I. Stern, “The environmental Kuznets curve”, In: C. J. Cleveland, Eds., Encyclopedia of Energy, Academic Press, San Diego, CA, 2004, 517-525. doi:10.1016/B0-12-176480-X/00454-X
[36] B. Yandle, M. Bjattarai and M. Vijayaraghavan, "Environmental Kuznets Curves: A Review of Findings, Methods and Policy Implications," Research Study 02.1 update, 2004, PERC.

[37] A. Leitão, "Corruption and the Environmental Kuznets Curve: Empirical Evidence for Sulphur,” Ecological Economics, Vol. 69, No. 11-12, 2010, pp. 2191-2201. doi:10.1016/j.ecolecon.2010.06.004 